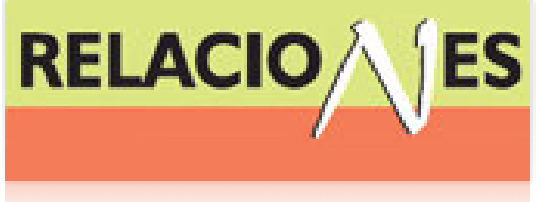

Relaciones. Estudios de historia y sociedad ISSN: 0185-3929

relacion@colmich.edu.mx

El Colegio de Michoacán, A.C

México

Tapia Tovar, Evangelina; Zalpa, Genaro

La corrupción a la luz de los dichos y refranes

Relaciones. Estudios de historia y sociedad, vol. XXXII, núm. 126, 2011, pp. 21-65

El Colegio de Michoacán, A.C

Zamora, México

Disponible en: http://www.redalyc.org/articulo.oa?id=13718501002

- Cómo citar el artículo

- Número completo

- Más información del artículo

Página de la revista en redalyc.org

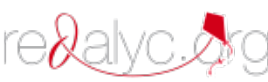

Sistema de Información Científica

Red de Revistas Científicas de América Latina, el Caribe, España y Portugal

Proyecto académico sin fines de lucro, desarrollado bajo la iniciativa de acceso abierto 


\title{
La corrupción a la luz de los dichos y refranes
}

\author{
Evangelina Tapia Tovar* \\ Genaro Zalpa \\ UNIVERSIDAD AUTÓNOMA DE AGUASCALIENTES
}

\begin{abstract}
El artículo aborda el estudio de la corrupción a partir de los dichos y refranes, que a través de generaciones han vertido su peculiar sabiduría para ayudar al ciudadano común a construir una representación significativa de su realidad; los refranes se utilizan como herramienta para tratar de hacer visible, a través del lenguaje, conductas, valores y representaciones mentales de lo que hemos llamado la cultura popular de la corrupción.
\end{abstract}

(Corrupción, refranes, cultura popular, vida cotidiana, lenguaje de la corrupción)

\section{INTRODUCCIÓN}

E

n este trabajo se aborda el estudio de la corrupción desde el lenguaje, en particular desde el habla lapidaria porque ella encierra las creencias y valores que han perdurado a través de los años en nuestra sociedad. No es un estudio de las palabras en sí mismas, sino del habla lapidaria como una producción cultural que nos permite la comprensión de algunos aspectos que intervienen en el fenómeno de la corrupción como un elemento de la cultura. Se trata de hacer visibles significados que alimentan una forma de actuar que, por su frecuencia, parecieran ser algo natural y normal, pero que pueden constituir conductas ilegítimas, poco éticas y hasta ilegales.

$\mathrm{El}$ artículo tiene ocho partes. En la primera se presenta al refrán como una forma lingüística que concentra rasgos culturales que han

*(etapia@correo.uaa.mx) (gzalpa@correo.uaa.mx) 
sido transmitidos a través de generaciones. En la segunda se plantea la definición de refrán y la perspectiva desde la que se hace uso de él en este trabajo. En la tercera se bosqueja el problema a partir de los índices de percepción de la corrupción elaborados por Transparencia Internacional. En la cuarta se presenta la problemática para definir la corrupción y los puntos de vista que son tomados en cuenta para identificar algunos conceptos específicos que constituyen lo que hemos llamado el lenguaje de la corrupción, el cual se presenta en la quinta parte, para vincularlo en la sexta con los refranes. En la séptima se presentan los refranes más relacionados con la corrupción a partir de la opinión de una muestra integrada por quinientos habitantes del centro de la República Mexicana. En la octava se hace el análisis de cuatro de los refranes más relacionados con la corrupción: El que no transa no avanza. ¿Cómo nos arreglamos? Más vale tener palancas que dinero y El gandalla no batalla. El artículo termina con la elaboración de algunas conclusiones.

\section{EL REFRÁN EN LA VIDA COTIDIANA}

El que se viere solo y desfavorecido, aconséjese con los refranes antiguos; así dice un viejo dicho que refleja la sabiduría popular que nos han heredado nuestros ancestros. Si bien, cada vez escuchamos menos estas expresiones, rescoldos de un arte barroco tan arraigado en el habla de los mexicanos, todavía los refranes tienen mucho que decir sobre la cultura de quien los usa. "El estudio de los refranes de un pueblo, como el mexicano, es como una estratigrafía de su cultura, intereses, ideologías, sueños, frustraciones, conflictos y cosas así". ${ }^{1}$

Antaño la gente hacía uso cotidiano de los refranes para expresar su sentir sobre aquello que le acaecía a diario, sin importar su nivel educativo, su estrato económico o su género. Aunque el refrán también encontró su lugar dentro del lenguaje culto e incluso en algunos textos literarios donde servían como pequeñas dosis de sabiduría para aquellos menos cultivados que los asumían como referencia obligada

\footnotetext{
${ }^{1}$ Herón Pérez Martínez, Refrán viejo nunca miente, Zamora, El Colegio de Michoacán, 1997, 21.
} 
GráfICA 1: Rangos de edad/grado de utilización de los refranes

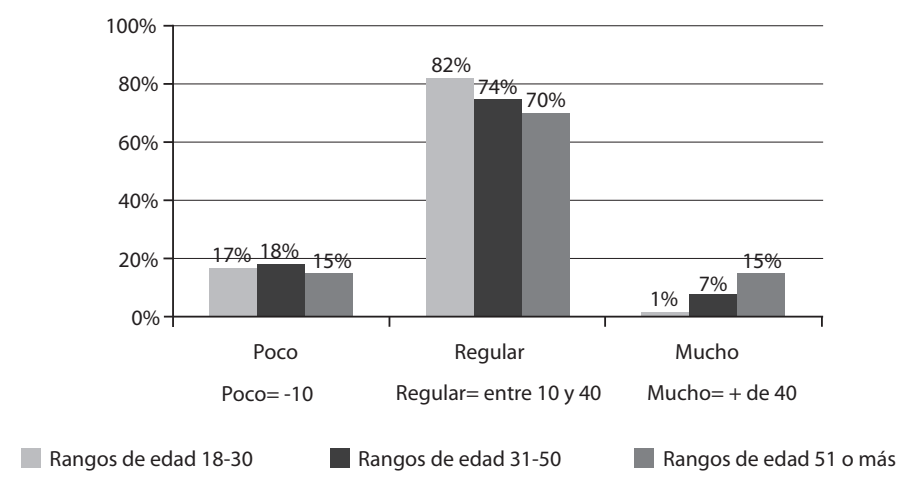

Fuente: Elaboración propia.

en su hablar cotidiano, en la actualidad los refranes son un adorno para el habla popular, perdiendo su vigencia en el lenguaje culto.

En los albores del siglo XXI, el segmento social que con más frecuencia hace uso de los refranes es el de las personas de mayor edad. Sin embargo, las nuevas generaciones también los conocen y usan un pequeño repertorio, muchas veces modificado por nuevas situaciones con las que los relacionan, o incorporando vocablos más conocidos. Esto se aprecia en la información arrojada por un cuestionario aplicado en la ciudad de Aguascalientes durante los tres primeros meses del 2009, en la que se puede conocer qué tan usados son los refranes, no sólo en Aguascalientes, sino también en regiones circunvecinas. ${ }^{2}$ La gráfica 1 ofrece elementos para diferenciar el uso de los refranes por grupos de edad.

Todo parece indicar que los refranes son usados por los distintos grupos de edad porque son "un saber de todos, se construyen con frases del dominio público que en general reproducimos, pero que también inventamos"3 y actualizamos según los requerimientos de

${ }^{2}$ De los encuestados, 65.4 por ciento nació en Aguascalientes; 13.6 en el Distrito Federal; 5.8 en Jalisco; 4.0 en Zacatecas; y 1.8 en San Luis Potosí.

${ }^{3}$ Josefina Guzmán y Pedro Reygadas, De refranes y cantares tiene el pueblo mil millares I. Refrán mexicano y discurso: tipología, campos y estructuras recurrentes en el universo de la oralidad, San Luis Potosí, UAsLP, Unidad de Publicaciones de El Colegio de San Luis, 2009, 13. 
CuAdro 1. Grado en que los refranes son utilizados por clase social (Resultados porcentuales)

\begin{tabular}{lccc}
\hline Nivel socioeconómico* & Poco & Regular & Mucho \\
\hline Bajo & 74 & 63 & 76 \\
Medio & 24 & 34 & 20 \\
Alto & 2 & 3 & 4 \\
\hline Total & 100 & 100 & 100 \\
\hline
\end{tabular}

Fuente: Elaboración propia. Nota: ${ }^{*}$ Medido de manera indirecta, a partir del indicador "número de focos en casa”.

cada uno, lo que también permite un uso diferenciado según el nivel socioeconómico, aunque quienes más los utilizan, según el cuadro 1 , derivado del mismo estudio, son las personas de clase baja: Pérez Botello ${ }^{4}$ señala que los refranes están fuertemente arraigados dentro de la cultura popular; su presencia se percibe tanto en el medio rural como en los centros urbanos, y en los medios masivos de comunicación (los locutores de radio o los conductores de programas televisivos los emplean constantemente y forman parte del diálogo de las telenovelas y de las películas).

Nuestra vida social se construye a través de las diferentes formas de comunicación que integran la cultura, la cual "está estructurada como un magno sistema semiótico cuyos textos, organizados jerárquicamente, remiten a una extensa gama de lenguajes". ${ }^{5}$ La vida cotidiana se construye a través de esa parte de la cultura que es el sentido común, que en gran parte se expresa a través de los refranes.

\footnotetext{
${ }^{4}$ María Teresa Pérez Botello, "El refrán como texto oral y escrito", en Estudios Sociales, nueva época, núm. 2, 2007, 183-197, 188.

${ }^{5}$ Herón Pérez Martínez, En pos del signo. Introducción a la semiótica, Zamora, El Colegio de Michoacán, 1995, 14. 


\section{DEFINICIÓN DE REFRÁN}

Existen diferentes enfoques que se pueden usar para definir al refrán. María Teresa Pérez Botello lo hace, a partir del punto de vista lexicológico, señalando que el concepto proviene tanto de la palabra francesa refrain, sinónimo de estribillo, cantinela, como del vocablo latino dictus. Herón Pérez, por su parte, señala que

En la actualidad, son dos las principales propuestas de explicación etimológica del vocablo "refrán": la más antigua de ellas, se remonta a don Sebastián de Covarrubias para quien la palabra "refrán" proviene del verbo latino referre [...] (que) alude al hecho de que se trata de textos que andan de boca en boca.

La segunda opinión, [...] muy difundida en la actualidad entre los etimólogos como Corominas, hace derivar el término "refrán" del verbo latino frangere, que significa "romper" o "quebrar". 6

A partir de estas dos posibles explicaciones, Herón Pérez define los refranes como

expresiones sentenciosas, concisas, agudas, endurecidas por el uso, breves e incisivas por lo bien acuñadas, que encapsulan situaciones, andan de boca en boca, funcionan como pequeñas dosis de saber, son aprendidas juntamente con la lengua y tienen la virtud de saltar espontáneamente en cuanto una de esas situaciones encapsuladas se presenta.

Esta perspectiva le da una dimensión social e histórica al refrán, porque enfatiza la significación que tiene para sus hablantes, en cuanto que concentra elementos cotidianos que son estructurados de ciertas maneras para incorporar el saber que se va heredando de una generación a otra; son como pequeños consejos basados en la experiencia pasada, pero adaptados a nuevas situaciones. Por su distintiva característica de ser locuciones de la tradición oral, es muy

${ }^{6}$ Herón Pérez Martínez, "Refranes y refraneros", en Arturo Chamorro Escalante, ed., Sabiduría popular, Zamora, El Colegio de Michoacán, 1997, 73.

${ }^{7}$ Herón Pérez Martínez, Refrán viejo nunca miente, p. 29. 
fácil la transmisión de los conocimientos que aportan para todo aquel que los quiera recibir, lo que los hace accesibles y populares.

En sus vastos estudios sobre el refrán, Pérez Martínez señala que el refrán tiene dos funciones que están estrechamente ligadas con sus orígenes: ser un texto parásito y romper la monotonía del discurso. La primera función se refiere a la necesidad que el refrán tiene de insertarse en un texto mayor para ser comprendido: el refrán no tienen un significado único, su interpretación está relacionada con el todo del habla (lugar, momento, personas, situación, cultura, etcétera), y por ello no todos los individuos pueden interpretarlos correctamente. La segunda función está sustentada en sus raíces etimológicas que remiten al verbo refráher, antes fránhe (en la lengua de Oc: romper) y que se refería a su uso para romper la estrofa y hacerla más ágil, menos monótona; es esta función la que fundamenta el papel ornamental del refrán dentro de la escritura y el habla culta presente en tantos textos clásicos de la literatura mundial entre los que destaca El ingenioso hidalgo don Quijote de la Mancha, texto en donde encontramos una gran cantidad de refranes que sirven tanto para instruir a Sancho Panza como para adornar el texto.

La primera función es la que sustenta este trabajo, pues ayuda a conocer tanto los significados que la gente les atribuye a los refranes al relacionarlos con textos más amplios, como a ir más allá y tratar de rehacer los contextos pertinentes para cada refrán relacionado con la corrupción para, a partir de ellos, tratar de reconstruir los significados socialmente creados sobre los elementos que están presentes en la vida cotidiana de los sujetos y de esta manera hacer evidentes algunos de los rasgos de lo que podría llamarse cultura popular de la corrupción.

Herón Pérez plantea que el refrán como texto puede ser estudiado desde diferentes disciplinas, pero para el caso de la sociología, que es desde donde lo estamos abordando, es considerado como portador de una sabiduría heredada de los ancestros, y por ello dotada de una autoridad reconocida socialmente que los hace funcionar como

axiologías que alimentan el hablar cotidiano, como dice Luis Alonso Schökel, cual 'una oferta de sensatez' de los pueblos, una especie de sabi- 
duría creadora de tipo práctico que nace de una experiencia tan variada y rica como la vida misma [...] Esta sensatez fundamental a la que remiten los refranes no es una sensatez individual: es, sí, la sensatez colectiva de la que se alimenta la moralidad popular. ${ }^{8}$

Vale la pena hacer manifiesto que cuando nos referimos al refrán lo hacemos de manera muy amplia, para incluir en este vocablo expresiones que, en sentido estricto, son figuras lingüísticas distintas, pero con una función similar. Pérez Martínez también utiliza el concepto de refrán en este sentido amplio; en el siguiente cuadro se pueden visualizar claramente las diferentes formas paremiológicas que son asimiladas en esta concepción amplia del refrán:

CuAdro 2: Ubicación del refrán dentro de las formas breves

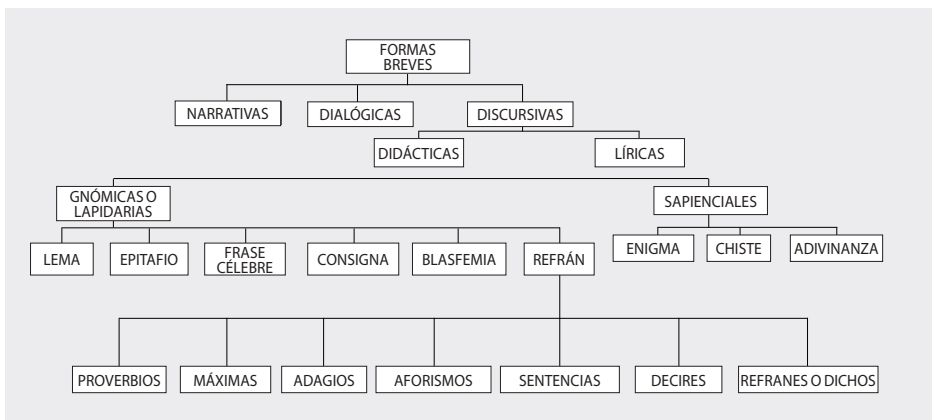

Fuente: Elaborada a partir de la propuesta de Herón Pérez Martínez, en Refrán viejo nunca miente, Zamora, El Colegio de Michoacán, 1997, 54.

En el cuadro se aprecia que el refrán, en un sentido estricto, es una forma discursiva de tipo didáctico, gnómica o lapidaria; pero en un sentido más amplio, contempla otras expresiones breves más específicas: el proverbio, la máxima, el adagio, el aforismo, la sentencia, el decir, el dicho y el refrán. Todas estas variantes cumplen la función comunicativa que aquí se pretende destacar, porque más allá de una

${ }^{8}$ Herón Pérez Martínez, El hablar lapidario: ensayo de paremiología mexicana, Zamora, El Colegio de Michoacán, 1995, 82-83. 
definición de diccionario, interesa una que sea funcional para su análisis, que muestre su relación con el habla cotidiana, espacio donde el refrán adquiere sentido a partir de un texto mayor y en un contexto específico, la vida cotidiana, en la que se inserta como sentido común, como moraleja o argumentación indiscutible.

Como se ha dicho, el refrán no tiene un significado único, y su interpretación está relacionada con la situación específica en que se usa. Dado su carácter de codependencia suele aludir a un texto mayor, el sentido común, que no se dice pero está como telón de fondo para los hablantes que lo comparten; por tanto, para comprender el sentido y poder usar adecuadamente el habla lapidaria es necesario ser nativos de la misma cultura o al menos conocerla.

Estudiar el habla para identificar elementos culturales implica la necesidad, y a la vez la imposibilidad, de congelar en el tiempo y en el espacio algo que es dinámico e irrepetible; sin embargo, el habla lapidaria sirve como un ancla en ese vertiginoso mar. El refrán constituye un elemento central del habla lapidaria, por lo mismo, de manera análoga a lo propuesto por Margit Frenk para el estudio del folclor vivo, se le considerará como algo muerto para facilitar su estudio: "Sacar el folklore de su contexto vital significa inmovilizar aquello que sólo existe en virtud de su incansable movimiento. Pero no podemos estudiar la mariposa mientras vuela; tenemos que clavarle el alfiler y sujetarla, exánime, al tablero". ${ }^{9}$ El estudio del habla popular requiere de ordenar y clasificar la disparidad del discurso que la gente habla de manera ordinaria para así identificar la cosmovisión social de cada grupo, es por eso que el habla lapidaria se constituye como una herramienta analítica para el estudio de la cultura.

Según Herón Pérez "El rasgo distintivo más importante de los refranes [...] es de índole discursiva y se refiere a la función entimemática que el habla de una cultura le asigna en el argumentar cotidiano", ${ }^{10}$

\footnotetext{
${ }^{9}$ Margit Frenk, "Folklore vivo/folklore tránsito: en torno al cancionero folklórico de México", en Arturo Chamorro Escalante, ed., Sabiduría popular, Zamora, El Colegio de Michoacán, 1997, 33.

${ }^{10}$ Herón Pérez Martínez, "La investigación paremiológica en México", en Herón Pérez y Raúl E. González, eds., El folclor literario en México, Zamora, El Colegio de Michoacán, Universidad Autónoma de Aguascalientes, 2003, 241.
} 
por ello, cuando se usa en las conversaciones diarias, la cultura de los hablantes sirve como telón de fondo para que se sobreentienda el sentido del refrán; es como un silogismo abreviado que en la mayoría de las ocasiones sólo tiene dos elementos: antecedente y consiguiente, y se completa con el saber que el grupo social comparte, por lo que tanto su interpretación como su uso no son arbitrarios.

\section{LA CORRUPCIÓN}

En México, como en muchos otros países, la corrupción es un fenómeno generalizado y visible a partir de la última década del siglo xx, en la que se percibe como un problema social que se debe erradicar. Desde entonces se han firmado acuerdos internacionales, se han implementado programas y se han destinado recursos para tal fin, sin mucho éxito. Al menos así lo revelan los datos generados por Transparencia Internacional. Las mediciones que ha aportado constituyen una referencia obligada para conocer cómo ha evolucionado la percepción del fenómeno de la corrupción en nuestro país entre los observadores internacionales (véase cuadro 3 ).

Este índice IPC mide, en una escala de 0 a 10, los niveles de percepción de la corrupción en el sector público de diferentes países. Se trata de un índice compuesto, obtenido a partir de otros índices elaborados por expertos y hombres de negocios. Para una mejor interpretación de este índice se puede confrontar con el cuadro 4.

Para organismos como Transparencia Internacional, "La corrupción ha dejado de ser vista sólo como un asunto de moral y ética, estático e inmutable para cierto tipo de individuos o sociedades.

Cuadro 3: Índice de Percepción de la Corrupción (IPC) 2001-2009

\begin{tabular}{llllllllll}
\hline Año & 2001 & 2002 & 2003 & 2004 & 2005 & 2006 & 2007 & 2008 & 2009 \\
\hline Índice & 3.7 & 3.6 & 3.6 & 3.6 & 3.5 & 3.3 & 3.5 & 3.6 & 3.3
\end{tabular}

Fuente: Elaborado a partir de los datos de Transparencia Internacional. 
CUADRO 4. Rangos para interpretar el IPC

\begin{tabular}{ll}
\hline Valor del indice & Interpretación \\
\hline 0 & Máxima corrupción \\
0 a 3 & Corrupción gravemente extendida \\
3 a 5 & Serio problema de corrupción \\
6 a 10 & Corrupción tolerable \\
\hline
\end{tabular}

Fuente: Elaborada a partir de la información de Transparencia Internacional.

Cada vez más, la corrupción se percibe como una conducta humana que obstaculiza el desarrollo humano". ${ }^{11}$

Como en otros países, en México se ha dado el combate a la corrupción para erradicar el problema y para atender la presión de organismos internacionales que condicionan créditos, inversiones y apoyos internacionales a la disminución de esta traba. Sin embargo, a pesar de los esfuerzos, se ha hecho evidente la falta de resultados y, por ende, la necesidad de analizar la problemática abordándola desde diferentes perspectivas. La especificidad de este trabajo radica en evidenciar a partir del estudio del habla cotidiana, y en especial de los refranes, algunas conductas, valores y representaciones mentales que se relacionan con la corrupción, pero que están tan integradas en nuestra cultura que pasan desapercibidas para la mayoría.

\section{DEFINICIÓN DE CORRUPCIÓN}

Definir este concepto conlleva toda una problemática vasta y complicada. Genaro Zalpa ${ }^{12}$ presenta un abanico de definiciones que van desde lo estrictamente legal hasta lo religioso y moral, pasando por lo cultural e histórico, en donde se puede apreciar que aunque existe una gran cantidad de definiciones, éstas serán pertinentes según el

\footnotetext{
${ }^{11}$ Corrupción en México en http://www.bajaeco.com/hablemos/corrupcion.cfm (consultada 6/XII/2009).

${ }^{12}$ Genaro Zalpa, ¿No habrá manera de arreglarnos? Corrupción y cultura en México, en proceso de publicación.
} 
propósito del enfoque. Así, en un cierto país, si lo que se quiere es castigar un delito de corrupción, habrá que ir al marco jurídico para establecer los rasgos que tipifican esa infracción; en cambio, si lo que se quiere es condenar la falta basados en la moralidad y las buenas costumbres, los criterios y conductas sancionables serán diferentes.

Un enfoque indispensable como punto de referencia para los estudios sobre corrupción es el propuesto por Transparencia Internacional, retomado por el Banco Mundial y Transparencia Mexicana, que señala que "La corrupción es la utilización de un cargo, el poder y los recursos públicos, para beneficio personal". ${ }^{13}$ Además, se tipifican cinco manifestaciones de la corrupción: soborno y su contraparte el cohecho, el peculado, el fraude, la extorsión y el favoritismo, también conocido como clientelismo o tráfico de influencias. Si bien, todas esas conductas son consideradas corruptas, la medición que este organismo realiza se enfoca únicamente a la medición del soborno.

Para este trabajo se tomarán, además de las anteriores, dos perspectivas más para tratar de definir el concepto en un acercamiento más microsocial. El primer enfoque es el que se fundamenta en la opinión pública sustentado en lo cultural e histórico. Es decir, se considerará como corrupción aquello que para la gente lo sea, todo aquello que de convertirse en conocimiento público conduciría al escándalo; esto implica que el reconocimiento de un acto como corrupto depende de la cultura, de tal suerte que un comportamiento escandaloso en un país, podría considerarse normal en otro. Definir la corrupción de esta manera, nos ubica en un lugar y un tiempo específico, pero dificulta cualquier medición general de ella. Dentro de esta concepción, Aroca plantea que puede haber tres tipos de corrupción: la blanca, la negra y la gris.

La corrupción blanca se emplea para referirse a prácticas que no son reconocidas como corruptas ni por la opinión pública ni por las minorías. En otras palabras, la corrupción está tan completamente integrada en una cultura que ya ni siquiera se percibe el problema [...] La corrupción negra tiene el

${ }^{13}$ Transparencia y combate a la corrupción, en http://www.ciad.mx/contraloria/ transparencia.html (consultado 9/IV/2010). 
mismo consenso, pero al revés: todos, minorías y ciudadanos, están de acuerdo en estigmatizar ciertas prácticas. El desacuerdo aparece en la opción gris: lo que unos definen como corrupción otros no lo consideran como tal. Es en este desajuste en donde hay riesgo de que aparezca el escándalo, en el choque entre las percepciones de unos y las prácticas de otros. ${ }^{14}$

Para este estudio, interesa considerar la corrupción blanca y gris vista desde el sujeto, es decir, en voz del ciudadano de carne y hueso que en su vida cotidiana vive la cultura de la corrupción casi sin darse cuenta, y explica o justifica algunas conductas a la luz de la filosofía popular que le ha sido heredada por otras generaciones; pero que es interpretada y actualizada en realidad inmediata: en el aquí y ahora.

La segunda perspectiva para definir la corrupción, la cultural, la ubica en un tiempo y lugar específicos, de tal manera que para un grupo social algo puede ser considerado corrupto y para otro no, o bien, en un momento histórico específico algo puede ser considerado como normal y en otro ser objeto de alguna sanción social o legal. Dentro de esta línea de análisis se encuentra Claudio Lomnitz, ${ }^{15}$ quien le da especial importancia al contexto específico para definir si una acción se califica como corrupta o no. El autor plantea que la mayoría de los científicos, políticos y ciudadanos saben lo que es la corrupción porque se trata de

[...] una categoría cultural que forma parte del discurso político común e incluso del sentido común. Por ello, para poder aprovechar en todo su potencial el estudio de la corrupción tenemos que comenzar no por un intento de reducir el concepto a una categoría analítica clara y precisa, sino [...] hacer de los usos del término un objeto de estudio. ${ }^{16}$

Desde este enfoque es explicable que una persona utilice sus influencias o su puesto para ayudar a familiares y amigos a conseguir

${ }^{14}$ Rubén Aroca, Corrupción, elites y democracia, en http://www.monografias.com/trabajos5/corrupc/corrupc.shtml

${ }^{15}$ Claudio Lomnitz, coord., Vicios públicos, virtudes privadas: la corrupción en México, México, CIESAS/Miguel Ángel Porrúa, 2000.

${ }^{16} I d .$, p. 13. 
trabajo, evitar un trámite, evadir una multa o conseguir un contrato sin sentirse culpable por ello; porque existen en su grupo familiar, social o cultural obligaciones que orientan su actuar que relega a segundo plano las obligaciones administrativas o legales, sobre todo en aquellos casos en los que no hay una clara definición para separar lo legal de lo ilegal, o cuando la impunidad es muy frecuente. También es posible entender que el uso y significado de ciertas palabras, en ciertos contextos, con grupos específicos y en situaciones concretas, tiene una historia que se materializa en el momento en el que un hablante dice algo a su interlocutor, que a su vez está en condiciones de entender conceptos que forman parte del habla cotidiana.

\section{El LENGUAJE DE LA CORRUPCiÓN}

En países como el nuestro, la corrupción se presenta camuflada por expresiones elaboradas con una añeja artesanía lingüística, donde "La corrupción jamás se reconocerá como tal. Nombrarla es una muestra de infinito mal gusto", ${ }^{17}$ jamás se expresa de manera directa, pues eso, en palabras de Dehesa, sería un impudor intolerable para la moral y las buenas costumbres.

El ceremonial de la corrupción exige la construcción de una realidad paralela donde se utilice un lenguaje diferente: se trata de las mismas palabras pero con una significación distinta que para ser comprendidas deben ser escuchadas por alguien que conozca a fondo la cultura del lugar o del grupo. "Si en la realidad legal existe el dinero, en el trasmundo corrupto existe la 'marmaja' y la 'lux'. Si el Banco de México emite billetes de mil, de quinientos y de cien pesos, en las catacumbas de la movida existen las 'milanesas', los 'quiñones' y los 'ciegos'". ${ }^{18}$

Cuando no se conocen los códigos de esta cultura es difícil realizar exitosamente una transacción. "Aquí es donde fracasan los grandes corruptores internacionales que llegan con los billetes en la mano y

\footnotetext{
${ }^{17}$ Germán Dehesa, ¿Cómo nos arreglamos? Prontuario de la corrupción en México, México, Editorial Diana, 2001, 23.

${ }^{18} I d .$, p. 40.
} 
nos ofenden gravemente al preguntarnos cuánto hay que dar para obtener la concesión para la fabricación de lápices bicolores y la posterior obligatoriedad de su uso en todas las escuelas nacionales". ${ }^{19}$

En México, la corrupción opera de otra manera: no tan evidente pero sí efectiva, pues no se llama por su nombre. Existe un campo semántico específico donde palabras como movida, arreglo, transa, acuerdo, negocio, hueso, entre, palanca adquieren un significado adicional en el habla popular. De hecho casi cualquier palabra puede ser usada "menos aquellas que indiquen corrupción. Así, en una transacción corrupta, ninguna de las partes podrá hablar de cohecho o de dinero mal habido. Utilizará expresiones tan bellas y diáfanas como 'cooperación', 'compensación'”, ${ }^{20}$ entre otras que deberán ser comprendidas por el negociador para que la transacción se pueda desarrollar, casi siempre con un barniz de legalidad, porque eso será lo que le de la legitimidad dentro de la sociedad.

La legitimidad, elemento indispensable en los actos de corrupción, proviene de dos fuentes: la primera es que debe parecer legal, esto es, que aunque existan elementos de ilegalidad (trámites no cumplidos o firmas rápidas), el tramite debe parecer normal, ser maquillado de legalidad para que no se note; por ello, casi siempre en el camino que sigue un trámite corrupto, se "salpica" a todos los involucrados, tanto con dinero, como con compromisos, favores y podredumbre.

El segundo aspecto que legitima socialmente la corrupción tiene que ver con una idea más o menos generalizada entre los ciudadanos de que el sistema está mal, que es injusto e inoperante, por lo que se hace necesario buscar vías alternas que ayudan a lograr cierta justicia personal: así, el burócrata que pide una cooperación para que cierto trámite se agilice lo justifica diciendo que es tan poco lo que le pagan que esa cooperación servirá para lograr un ingreso decente; igual pasa con el policía o el agente de tránsito que hace como que no ve ciertas cosas a cambio de una ayuda (moche, lux, billete o como le quiera llamar). La legitimidad social se logra a

${ }^{19} I d .$, p. 25.

${ }^{20}$ Id., p. 51. 
partir de criticar al sistema en su conjunto.

Es en este momento, el de la argumentación social o personal para legitimar actos corruptos, cuando se incorporan algunas expresiones o frases hechas del habla lapidaria: dichos y refranes que ayudan en el proceso de convencimiento, en la argumentación que se da en torno al hecho. "¿Cómo nos arreglamos?", por ejemplo, podría ser una clara invitación a la corrupción en un contexto específico; expresar que "el que no transa no avanza" sería una justificación hacia un acto de corrupción; o "abogado de ricos mal de pobres" actuaría como crítica y evidencia de actos de corrupción que perjudican a la comunidad.

\section{LOS REFRANES Y LA CORRUPCIÓN}

El lenguaje es un mecanismo con el que el humano expresa su experiencia del mundo circundante y a la vez le sirve como herramienta para organizar esa construcción del mundo. De ahí que el refrán, como un hecho de la lengua, construya y transmita la cultura.

La lengua evoluciona y se desarrolla de acuerdo a las condiciones sociales, por ello es explicable que ciertos refranes perduren en la memoria social y en el habla cotidiana y otros no.

La vida de un refrán dentro de una comunidad depende de la vigencia de su función: cuando ya las circunstancias que provocaron su incorporación a la lengua cotidiana cambian o desaparecen, el refrán pierde vigencia y tiende a desaparecer. En algunos casos, el refrán sólo modifica su sentido paremiológico y se adapta, con otra función, a las nuevas circunstancias. ${ }^{21}$

Como se ha mencionado, el sentido o significado del refrán tiene una dimensión histórica y cultural; en su interpretación interviene el contexto social de referencia para que al ser expresado sea comprendido por los que escuchan, con la significación que el emisor quiere darle. El problema surge porque su acepción suele no ser literal, debe haber conocimientos y experiencias comunes para que

${ }^{21}$ Herón Pérez Martínez, Refrán viejo nunca miente, p. 35. 
sirvan como trasfondo para su comprensión; por ello es necesario explorar entre aquellos que usan los refranes para conocer sus rasgos argumentativos y sus contextos probables, destacando su uso social para llegar a una significación simbólica dentro de la cultura de la corrupción en la vida cotidiana.

Con ese fin, se realizaron entrevistas a profundidad a siete informantes, de manera individual, y a diez en una entrevista colectiva, además de la aplicación de quinientos cuestionarios estructurados. En los tres prototipos de obtención de datos se coincidía en que los refranes que hablan sobre la corrupción dependen de dónde, cuándo y quién los expresa; por tanto, abordar la corrupción desde los refranes implica un reto, porque aunque esa pequeña expresión encierra mucho de las creencias y valores del grupo social, es el contexto el que le da sentido. Para que se exprese es necesaria una situación social ad hoc que permita la inserción del dicho o refrán como una moraleja o consejo. Si esa situación social está relacionada con la corrupción, el refrán puede ser usado para justificar, legitimar o criticar esos actos.

Existen refranes aplicables a cada situación de la vida cotidiana, pues sirven como mecanismo legitimador de la tradición y la costumbre; puede usarse un refrán para criticar el interés por el dinero, por ejemplo, cuando se dice Para el diablo, la mejor ganzúa es el dinero, o bien justificar ese interés al expresar Más ablanda don dinero, que sermón de misionero, cuando es el dinero el medio para alcanzar algo por métodos donde la corrupción aparece, o llevarlo hasta el ámbito de la religiosidad popular cuando se expresa que Elsanto más milagrero, es san Dinero.

Cuando la corrupción es expresada como algo ordinario, vivida por todos, se legitima y se acepta como un mal tolerable; cuando se dice que la corrupción "está en todas partes" o que "la corrupción somos todos", en lugar de angustiarnos o discutir, nos reímos. ${ }^{22}$ Aparece disimulada en expresiones que denotan la necesidad de ahorrar tiempo, agilizar trámites, aprovechar las oportunidades y dar o pedir gratificaciones "por favores recibidos". La corrupción es maquillada con un lenguaje que la disimula, la hace menos ingrata y más llevadera.

${ }^{22}$ Germán Dehesa, op. cit. pp. 11-12. 


\section{REFRANES SOBRE CORRUPCIÓN}

Las temáticas abordadas en los refranes son muy variadas, pero a partir de la opinión de una muestra de 500 personas mayores de 18 años, se pudo identificar cuáles son las expresiones que en el centro del país son las que más se asocian con la corrupción.

Como se puede observar, la mayoría de los refranes asociados con la corrupción son aquellos que hablan de dinero y poder, incorporan un lenguaje especializado que remite al campo semántico de la corrupción (transa, móchate, movida, gandalla, palanca), u otras palabras que aunque no se relacionen directamente a actos de corrupción, denotan esa idea gracias al contexto en que se emplean.

\section{EJEMPLOS DEL USO Y SIGNIFICADO DE ALGUNOS REFRANES}

Después de identificar cuáles son los refranes más asociados por la gente con su idea de corrupción, lo siguiente es identificar el sentido paremiológico de cada uno de los refranes, entendiendo por ello el sentido propiamente argumentativo de cada uno de ellos, más allá del significado semántico del texto: es, digamos, una formulación encapsulada del valor discursivo de cada refrán, siguiendo el hilo temático de la corrupción. A manera de ejemplo, se hace el análisis de cuatro refranes, a partir de tres ejes: el primero especifica algunas de las características de sus hablantes; el segundo plantea conocer el sentido paremiológico del refrán; y el tercero destaca las implicaciones sociales que tiene el sentido del refrán en la vivencia diaria de la corrupción en las personas comunes. Los cuatro refranes son: El que no transa no avanza; ¿Cómo nos arreglamos?; Más vale tener palancas que dinero; y El gandalla no batalla.

\section{El que no transa no avanza}

Esta expresión, la más asociada con la corrupción según la opinión de 96 por ciento de la muestra integrada por 500 personas encuestadas para este estudio, es usada por 211 miembros de la muestra (42\%). De ellos, 131 son hombres y 80 mujeres; en cambio, de en- 
CuAdro 5. Los refranes más relacionados con corrupción (Resultados porcentuales)

\begin{tabular}{|c|c|c|}
\hline \multirow[t]{2}{*}{ Dicho o refrán } & \multicolumn{2}{|c|}{$\begin{array}{l}\% \text { que lo relaciona o } \\
\text { no con corrupción }\end{array}$} \\
\hline & Sí & No \\
\hline 1. El que no transa no avanza & 96 & 4 \\
\hline 2. ¿Cómo nos "arreglamos"? & 94 & 6 \\
\hline 3. Yo puedo más que tú; dijo el dinero a la justicia & 88 & 12 \\
\hline 4. El dinero abre todas las puertas & 85 & 15 \\
\hline 5. Con dinero baila el perro & 84 & 16 \\
\hline 6. Más vale tener palancas que dinero & 83 & 17 \\
\hline 7. Cuando el dinero habla, todos callan & 82 & 18 \\
\hline $\begin{array}{l}\text { 8. Aunque provenga de manos asquerosas, el dinero } \\
\text { siempre huele a rosas }\end{array}$ & 82 & 18 \\
\hline 9. Es como la ley de Herodes, o te "chingas" o te "jodes" & 82 & 18 \\
\hline $\begin{array}{l}\text { 10. Todo hombre tiene su precio, lo que hace falta es } \\
\text { saber cual es. }\end{array}$ & 82 & 18 \\
\hline $\begin{array}{l}\text { 11. Ladrón que roba a ladrón, tiene cien años de } \\
\text { perdón }\end{array}$ & 79 & 21 \\
\hline $\begin{array}{l}\text { 12. "Móchate", "Mochilas" o "Mochilas pa' los } \\
\text { cuadernos" }\end{array}$ & 78 & 22 \\
\hline 13. El dinero hace bueno lo malo & 76 & 24 \\
\hline 14. Poderoso caballero es "don Dinero" & 76 & 24 \\
\hline 15. Abogado de ricos, mal de pobres & 75 & 25 \\
\hline 16. La ocasión hace al ladrón & 75 & 25 \\
\hline $\begin{array}{l}\text { 17. El dinero no es la vida, pero sin dinero no hay } \\
\text { movida }\end{array}$ & 75 & 25 \\
\hline 18. El gandalla no batalla & 74 & 26 \\
\hline 19. Póngase la del Puebla & 74 & 26 \\
\hline 20. Póngase "guapo" & 73 & 27 \\
\hline
\end{tabular}

Fuente: Elaboración propia. 
GrÁficA 2: Uso del refrán El que no transa no avanza según escolaridad

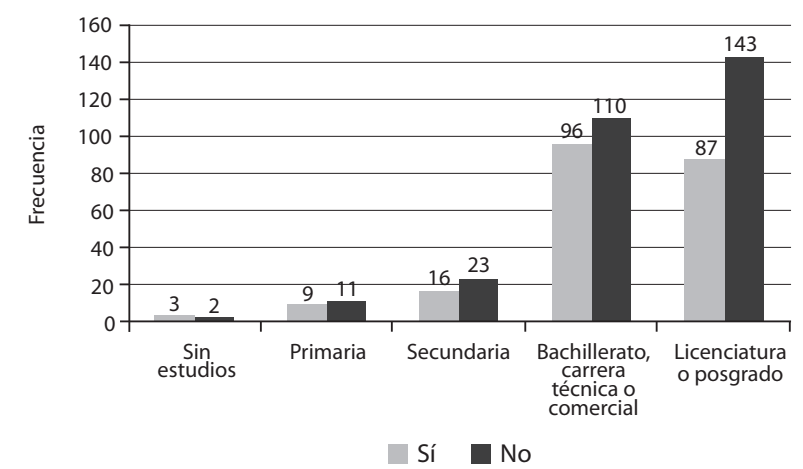

Fuente: Elaboración propia.

tre los que no lo usan la mayoría son mujeres, estableciendo una correlación de $\mathrm{Q}=38 \%$ entre el uso del refrán y el género de las personas. En cuanto a su uso por nivel de escolaridad, se puede concluir que a mayor escolaridad menor uso de este refrán.

Se observa que conforme aumenta el nivel de estudios disminuye la proporción de las personas que declaran utilizar este refrán, porque mientras entre la población sin estudios 60 por ciento lo utiliza, entre los de licenciatura y posgrado tan sólo lo hace 38 por ciento. Como se mencionó líneas arriba, el uso de refranes es más frecuente entre persona de mayor edad, sin embargo en este refrán no es así.

Como se puede apreciar, son los jóvenes los que más usan este refrán, puesto que mientras en este grupo declara usarlo 50 por ciento, entre los viejos es de 28 por ciento. En el grupo de los jóvenes se usa de manera indistinta transar y transear, y señalan que transar es más de caché23 y transear se usa más coloquialmente (en los diccionarios de mexicanismos sólo se encuentra transar). En general, este concepto se entiende como la acción de engañar a una persona para "sacar un beneficio [...] propio para bien personal de

${ }^{23}$ Elisa y Luis en entrevista grupal (13/X/2009). 
GráfICA 3. Uso del refrán El que no transa no avanza según edad

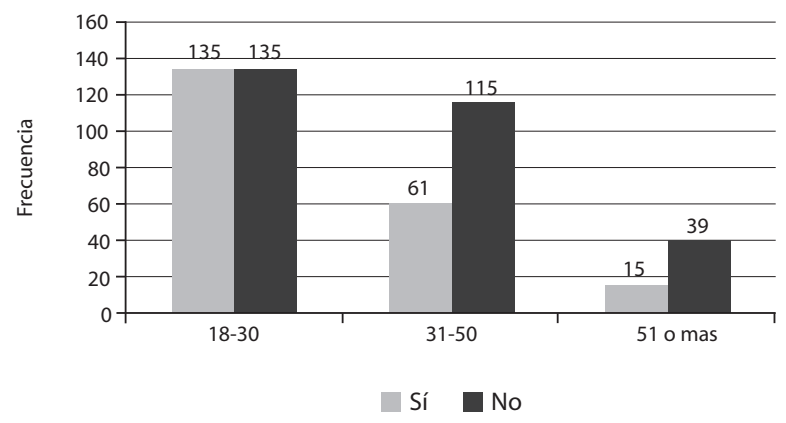

Fuente: Elaboración propia.

las situaciones, o sea no nada más en cuanto a dinero [...] también en oportunidades [...]"24

Según Chávez Torres, la palabra proviene de transacción, que es el concepto utilizado para referirnos a un negocio, trato, convenio, compromiso, contrato, o en general, cualquier asunto o gestión. En su uso coloquial, estos significados se han extendido más allá para llevarlos al campo del engaño, del negocio turbio, sucio o hasta ilegal. "La transa está convertida en aceite necesario para los negocios rápidos y de poca imaginación”. ${ }^{25}$ Para que la transa sea llevada a cabo se requiere, al menos, de dos actores que coincidan en el interés de realizar una operación por vías no legítimas.

Esta expresión aflora en el habla popular en tono de broma o en serio para hacer mofa o crítica de actitudes o acciones que pueden ser inadecuadas, injustas o hasta ilegales, así Iván nos dice: "Por ejemplo, una vez un amigo se robó unos gansitos de la tienda y yo le dije eso, le dije -no pues tú sabrás-. Y a manera de broma le dije ese dicho" ${ }^{26} \mathrm{El}$ refrán tiene la virtud de poder ser introducido con suma facilidad en casi cualquier acto del habla, y en este caso la broma

\footnotetext{
${ }^{24}$ Elisa en entrevista grupal (13/X/2009).

${ }^{25}$ Rafael Chávez Torres, "La transa económica", en Revista Escrutinio. La mirada critica, 8 de septiembre, 2009.

${ }^{26}$ Iván, en entrevista grupal (13/X/2009).
} 
encierra la crítica; el humor exterioriza el rechazo a la acción, pero suaviza la forma de decirlo.

En otras ocasiones, la transa puede significar la oportunidad de ganar adicionalmente algún dinero, como cuando se presenta la oportunidad de comprar algo barato y venderlo caro, aunque no quede claro si el origen del bien es legal o no, lo que justifica adquirir productos robados o piratas ${ }^{27}$ sin importar el daño social que ello puede ocasionar. Así lo muestra una de las narraciones obtenidas en la entrevista grupal con jóvenes, donde Luis dice: "una vez que yo fui a Tepito vi que mi hermano necesitaba comprar la refacción de un coche y salía como en 20 mil pesos y en Tepito, en una bodega la consiguió en 2 mil, pero le dijeron que era robada y mi hermano aun así aceptó". ${ }^{28}$ Son esas acciones cotidianas las que sostienen la corrupción a baja escala, porque "en la corrupción, el objetivo es siempre conseguir algo (por ejemplo, dinero, poder, riquezas materiales, etc.), independientemente de los medios que resulten necesarios. En la corrupción los fines justifican los medios, independientemente de toda ética". ${ }^{29}$

En la sociedad contemporánea, el éxito se convierte en una meta a la que se orientan los esfuerzos de los individuos, y para lograrla no importa a quién se pisotee; la transa se convierte en un medio para llegar al éxito. Quienes no optan por ese camino y prefieren ser respetuosos y decentes, no avanzan, se quedan estancados y son vistos como peligrosos para el sistema, o son considerados como tontos por no aprovechar las oportunidades. El contexto sociocultural en el que nace y crece el individuo define lo que tiene o no sentido para él, lo que le es significativo; en ese proceso de socialización los sujetos aprenden de manera consciente o no, voluntaria o involuntariamente, conductas habituales para el grupo social, "incluidas por supuesto las prácticas corruptas, que son anteriores al individuo, y, con mucha probabilidad, continuarán una vez que el sujeto haya muerto". ${ }^{30}$

\footnotetext{
${ }^{27}$ En México se les llama piratas a los productos que son copias pero se venden como originales, o que se reproducen sin autorización.

${ }^{28}$ Luis, en entrevista grupal (13/X/2009).

${ }^{29}$ Luis Fernández Ríos, Psicología de la corrupción y los corruptos, Granada, Grupo editorial Universitario, 1999, 49. Las cursivas aparecen en el texto original.

${ }^{30} I d$., p. 20.
} 
La transa que más se asocia con la corrupción es el soborno, conducta que mide Transparencia Mexicana desde 2001, por medio de una encuesta en la que pregunta sobre pagos indebidos realizados en 38 servicios públicos: "la encuesta registra las veces que un entrevistado declaró haber pagado una 'mordida' para realizar un trámite o recibir un servicio público" ${ }^{31}$ Pero en la vida diaria se da otro sinnúmero de transas que no son medidas por nadie, y muchas de ellas ni siquiera son asociadas con la corrupción por la mayoría de la población, para quienes las transas son las que hacen los políticos y no los ciudadanos; debido a eso, es perfectamente explicable que sea la transa en la administración pública y en la política la más relacionada con la corrupción.

La primera de ellas se hace más evidente y tiene un costo más medible tanto en el trámite de permisos, de licencias de construcción, autorizaciones para cambio de uso del suelo, permisos para vender licores, entre otros, así como para evitar tener problemas en las inspecciones; el objetivo perseguido por el ciudadano es no tener problemas y que se agilicen los trámites. La transa se agudiza en las grandes ciudades, aunque también se presenta en las pequeñas. "La demanda de servicios corruptos -es decir, la oferta de sobornosdepende del tamaño y estructura del Estado. Se pagan sobornos por dos razones: para obtener beneficios gubernamentales y para evitar los costos".$^{32}$ Es posible que en sociedades pequeñas, donde la mayoría de sus habitantes todavía se conocen, los problemas burocráticos se resuelvan con el apoyo de redes sociales basadas en la confianza (por palancas), más que con retribuciones económicas (por sobornos).

La transa política es menos evidente para el ciudadano común, pero ello no es obstáculo para que en el imaginario popular los políticos sean los corruptos por excelencia, imagen que es reforzada por las notas escandalosas sobre actos de corrupción en las que frecuentemente se ven envueltos, independientemente del color partidista,

\footnotetext{
${ }^{31}$ Corrupción en México en http://www.bajaeco.com/hablemos/corrupcion.cfm (consultada 6/XII/2009).

${ }^{32}$ Susan Rose-Ackerman, "La economía política de la corrupción”, en Ann Elliott Kimberly, La corrupción en la economía global, México, Limusa, p. 51.
} 
aunque todavía prevalece entre la mayoría de los entrevistados la asociación entre corrupción y político priista.

La transa o ser transa no es privativo de una clase social específica. Involucra a toda la escala social desde el vendedor ambulante hasta el secretario de estado, al diputado o al agente de tránsito, al funcionario que autoriza un permiso indebidamente, al ciudadano que lo solicita, al inspector que hace como que no ve, al que vende productos pirata, al policía que cuida a los criminales en lugar de velar por los ciudadanos, todos son ejemplos de acuerdos sustentados en la transa para ganar más. Lo peligroso de estos pactos subterráneos es que: "En múltiples ocasiones, crimen organizado, corrupción y estructuras de poder se hallan interconectadas", ${ }^{33}$ y ese dinero mal habido cobra su precio en sangre, o en cárcel cuando algo falla.

¿Cómo nos arreglamos?

Esta expresión que de manera explícita no pareciera decir mucho, fue relacionada con la corrupción por 94 por ciento de los encuestados; su uso concreto, en contextos específicos hace comprender que se trata de una invitación a la corrupción; por ello es importante lograr una comprensión de su uso en la vida social y establecer los límites que la misma sociedad ha impuesto a esta expresión, para comprender cuándo su uso implica elementos y conductas que pueden ser consideradas como malas o sucias y cuándo la pregunta no tiene esta connotación.

La persona que dice ¿cómo nos arreglamos?, hace suponer que está dispuesta a dar o hacer lo que sea con tal de conseguir lo que quiere, sabiendo que no es el procedimiento correcto para lograrlo. Esta breve enunciación constituye una clara invitación al mundo de la corrupción: "cuando una persona utiliza esa expresión está queriendo abrir espacios, $[\ldots]$ son los que quieren palancas, [...] los que quieren transar utilizan estas expresiones; desde luego que hay personas ingenuas que a veces la usan pero sin pensar en la extorsión, en la

${ }^{33}$ Luis Fernández Ríos, op. cit. p. 42. 
GRÁfICA 4. Uso del refrán ¿Cómo nos arreglamos? según el género

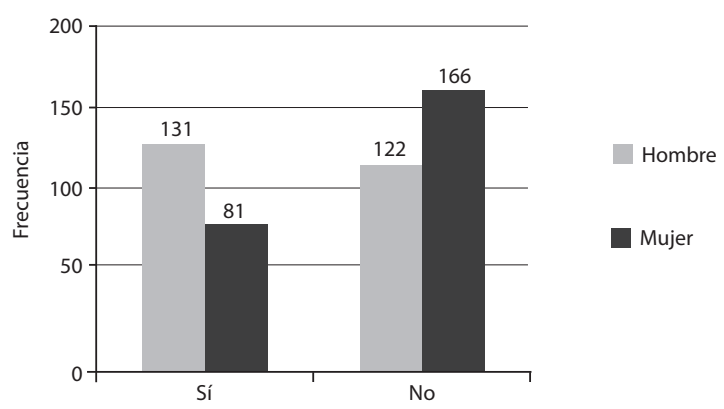

Fuente: Elaboración propia.

transa, o en la palanca" ${ }^{34}$ Se trata de un dicho popular que abre la puerta para todo tipo de transacciones ilegítimas, y cualquiera que lo diga, usuario o funcionario, está invitando al soborno o al cohecho, porque esta pequeña expresión encierra una clara invitación al arreglo, a la transa, al favor mal habido y a la extorsión. Esta expresión es más usual entre los hombres, como se aprecia en la gráfica 4.

Como lo hemos manifestado, la mayoría de las personas que hablan con refranes son hombres, y esta expresión no es la excepción, pues de entre las personas que usan este refrán (212), 62 por ciento son hombres y 38 por ciento mujeres. En lo que se refiere a la edad, se conserva la tendencia del uso general en los refranes: su uso es más frecuente, proporcionalmente hablando, entre las personas mayores de 50 ańos, que constituyen 44 por ciento, en cambio en el grupo inmediato anterior, los de 31 a 50 años, apenas lo usa 38 por ciento. De igual manera, conforme avanza el nivel de escolaridad, disminuye el uso de este refrán:

Como se aprecia en la gráfica 5, la proporción de las personas que usan este refrán es mayor entre los que no tienen estudios (60\%), o entre los que tienen primaria (45\%) y secundaria (49\%), que entre los que tienen licenciatura y posgrado (37\%), que, sin

${ }^{34}$ Entrevista con A. Pérez (20/III/2009). 
GráfiCa 5. Uso del refrán ¿Cómo nos arreglamos? según escolaridad

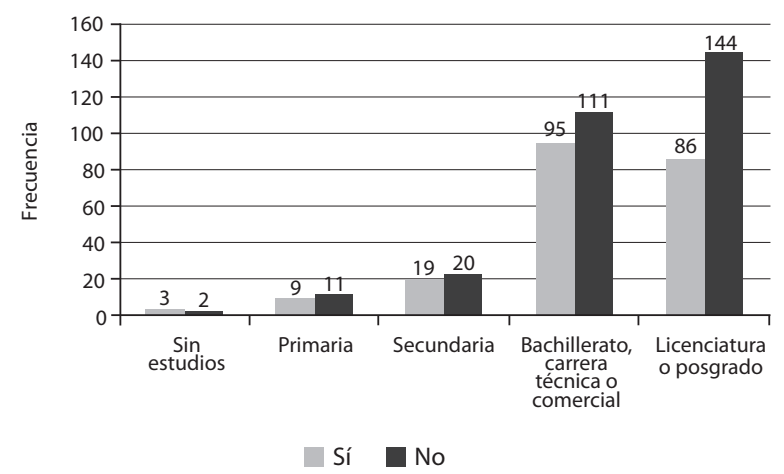

Fuente: Elaboración propia.

embargo, sigue siendo bastante alto, tal vez por la ambigüedad de la expresión; se trata de un dicho que aunque se relaciona directamente con la corrupción, es tolerado socialmente y muy usado.

El dicho aflora cuando el sujeto sabe que no se puede hacer o tener algo por las vías normales, es cuando plantea la pregunta como si fuera un anzuelo que el funcionario puede o no morder, eso depende de si es corrupto o no. La pregunta en sí misma parece no comprometer ni a uno ni al otro; se lanza al aire para ver si el escucha responde adecuadamente. Si uno u otro se ofende, siempre habrá una salida para allanar el equívoco, haciéndose el disimulado o diciendo que la pregunta no tiene ningún doble sentido. En este contexto, la palabra "arreglo" adquiere un sinnúmero de significados, y "arreglarse" implica la transgresión de una o varias reglas". ${ }^{35}$ En nuestra vida cotidiana "arreglarse" será un concepto frecuentemente utilizado en cualquier tipo de transacción de dudosa calidad moral, y aunque puede referirse a algo violatorio de la ley, frecuentemente no es así, simplemente se trata de acomodar algo de los procedimientos normales o de la ley para poder lograr un propósi-

${ }^{35}$ Germán Dehesa, op. cit., p. 16. 
to. Cuando hablamos de un arreglo, o de arreglar algo se trata de "Crear reglas instantáneas, personales, solapadas y sin más conveniencia que nuestro interés inmediato en contravenir y atropellar esas reglas generales" ${ }^{36}$

Existen funcionarios a los que fácilmente se les asocia con esta expresión: al mal burócrata de ventanilla o escritorio que quiere sacar ventaja complicando un trámite sencillo, con el afán de cobrar indebidamente por el servicio al usuario; al policía corrupto que detiene al ebrio consuetudinario, al drogadicto o a cualquier sospechoso con el único fin de conseguir un dinero extra. El agente de tránsito es considerado uno de los funcionarios más corruptos, sobre todo a partir de la época de Arturo Durazo Moreno, ${ }^{37}$ el Negro Durazo, cuando la podredumbre en el Departamento de Policía y Tránsito del DF, llegó a niveles tan escandalosos que motivó libros y películas sobre el hecho. La mayoría de los entrevistados narró experiencias con los agentes de tránsito relacionadas con esta expresión, por ejemplo uno de los entrevistados, el Sr. Eduardo, que es taxista, explicó que en ocasiones pareciera que tienen cierta consigna de detener a los taxistas, y por cualquier motivo quieren levantar infracciones, aunque realmente lo que quieren es pedir dinero: "ya cuando ven que de repente no le pagas, a ver tu licencia: —aquí esta; tu gafete, —aquí está; ¿placas?, — aquí están; ¿̨la verificación?, —aquí está; y todo se lo das. Pero, ¿sabes qué? No te puedo dejar ir... aunque sea dame pa'l cafecito". ${ }^{38} \mathrm{El}$ mismo Eduardo nos dice que en el transporte público el lenguaje es más directo que con los particulares, por lo que en la extorsión se da un regateo abierto y hasta ofensivo, sobre todo cuando dice: "le avientas 20 o 50 pesos"; tal vez la expresión no sea totalmente apegada a la realidad, pero sí muestra cierto desdén y desprecio a los agentes corruptos, en lugar del respeto que se le debería de tener a un agente que cuida y ayuda a los automovilistas.

Este informante expresa también que los agentes son más sutiles con los automovilistas particulares, a quienes llegan saludando y

${ }^{36}$ Germán Dehesa, op. cit., p. 24.

${ }^{37}$ Jefe de la policía del Distrito Federal, nombrado por su amigo José López Portillo, presidente de la República Mexicana de 1976 a 1982.

${ }^{38}$ Entrevista con Eduardo (7/IV/2009). 
pidiendo los papeles, casi siempre dando consejos de lo que no se debe hacer y la gravedad de la infracción que se cometió y el tiempo que perderá al tener que ir a pagarla, todo ello para que sea el mismo conductor el que haga la pregunta en cuestión (¿cómo nos arreglamos?) y en caso de que eso no suceda el agente la hará para evitarle "inconvenientes" al infractor que deberá decidir si "arreglar" el problema por la vía rápida o recibir su multa e ir a pagarla. Uno de los elementos que más motiva a los ciudadanos a entrar en la dinámica de la corrupción es precisamente la renuencia a hacer trámites que le quitarán tiempo y si de todos modos iba a pagar, pues prefiere hacerlo al agente de tránsito. Esto se da tanto entre particulares como entre trabajadores del volante, porque si optan por darle al agente 50 pesos el problema termina ahí (para ellos) y de otra manera "ya cuando le hacen a uno una infracción, según el artículo que sea, pero bajita la mano [...] a lo mucho pagas 80 pesos [...] pero la vuelta y el tiempo, por eso mejor jay' te va!, y no es que uno fomente la corrupción pero es que a veces es más práctico, mejor darle". ${ }^{39}$ En ocasiones es el mismo automovilista quien ofrece:

[...] a veces no quieren, según ellos son muy dignos, a veces tienen su estilo muy arriba, y les dice uno [...] mira — ¿sabes que onda?, ahí te va lo de la multa que me van a cobrar y no va a ser ni para ti; te voy a regalar esto, para que cuando llegues a tu casa cuando acabes de trabajar te compres tu refresco o tu cervecita. Mejor ¡disfrútalo ahora! ¿quién más se da cuenta, más que tú y yo?, nada más [nosotros] sabemos de la falta, no hay mas gente, ¿qué caso tiene que alimentemos al gobierno engordándolo más de todo lo que come?, mejor de que engorde aquél a que engordes tú, pues mejor que engordes tú ¿¿no? mejor saboréalo, y es cuando le llega uno a la persona de modo amable; $\mathrm{y}$ a veces —no pues ándale, pues ya vete”. ${ }^{40}$

Como se puede ver, también los ciudadanos reproducimos la corrupción cuando nos encontramos en situaciones problemáticas; es una manera de agilizar todo y porque pareciera ser un acuerdo en el

${ }^{39} \mathrm{Ibid}$. 
que las dos partes resultan beneficiadas; pareciera que los protagonistas de las prácticas corruptas son actores consensuales que compran y venden, intercambian prestaciones de forma voluntaria y todos salen ganando.

Con los policías federales es algo semejante pero más descarado porque si "tú chocas [le] pegas a un carro en un coche, un camión, equis, y tú tienes la culpa, si llega un federal, si llega un [...] cualquier corporación, tú le das una lana y aunque tú seas culpable te hace que tú seas inocente"; ${ }^{41} \mathrm{o}$ si algún documento no está bien o algo anda mal del vehículo, todo se arregla con dinero; así lo señala Marco Antonio, que es un conductor de trailer, quien conoce las formas que tienen los agentes de tránsito y los policías federales de caminos de diferentes lugares y dice que los más corruptos son los de Guadalajara, de Monterrey y de la ciudad de México, porque siempre los detienen y les piden dinero, los extorsionan con cualquier pretexto; en cambio en Aguascalientes, Guanajuato, Querétaro, Hidalgo o Coahuila es raro que los paren. Cuando se resisten a la extorsión, son amenazados con quitarles el cargamento o hasta el camión; en otras ocasiones los amenazan de muerte, sobre todo en lugares inhóspitos, donde no hay testigos que los ayuden. También hay zonas del país donde los agentes de tránsito piden dinero, pero de una manera todavía menos digna, de tal manera que Marco Antonio les dice rateros y hambreados: "en el estado de Tlaxcala pa' Veracruz, hay pueblos donde pasa la carretera y hay topes, y está el federal, así dicen [con los brazos abiertos], que como los Cristos, agarrando dinero de los camiones, de a 10 , de a 15 , de a 20 , de a como le den, día y noche". 42

Pero los más corruptos son los de la Agencia Federal de Investigación (AFI) y los de la Policía Federal Preventiva (PFP), porque ellos, además de extorsionarlos para que les den dinero, frecuentemente les "echan" droga en las revisiones o hasta les quitan el cargamento o el camión y los dejan tirados a mitad de la carretera, o hasta pueden llegar a matarlos. La única opinión favorable fue hacia los soldados

${ }^{41}$ Entrevista con Marco Antonio (03/XI/2008).

${ }^{42}$ Ibid. 
del ejército, pero todas las otras corporaciones policíacas que se encuentran a lo largo y ancho del país se caracterizan no sólo por pedir un soborno, sino más bien por extorsionar a los camioneros.

Vale la pena detenernos a reflexionar quién hace la pregunta: ¿cómo nos arreglamos? La creencia general es que se trata del oficial de tránsito, el federal de caminos o el funcionario público, y en muchos casos así se da, pero atendiendo al estereotipo que existe sobre ellos como corruptos, para muchos automovilistas es lo normal plantearles ellos la pregunta, sobre todo al agente de tránsito, al policía municipal o al funcionario de bajo rango que recibe los papeles, no así a oficiales de más rango o a los funcionarios importantes. "Cuando un conductor le ofrece soborno a un policía, los dos saben que la probabilidad de encontrarse nuevamente en algún circulo social es remota” ${ }^{\prime 3}$ y en el caso de todos los demás también; el ciudadano corrupto que tiene capacidad para sobornar, lo hace con agentes o funcionarios de menor rango que el propio porque considera que así puede comprarlos. En cambio, cuando se trata de personas de más jerarquía social la estrategia es distinta, más velada, usando la triangulación para que sea un conocido de más rango quien pida el favor. En cambio, cuando es el policía federal de caminos o el de la AFI, es la amenaza de que se volverán a encontrar la que facilita la extorsión; el poder está en el funcionario corrupto. Esta expresión puede llevarnos desde el favor para agilizar un trámite hasta la extorsión, pasando por el soborno y el cohecho.

\section{Más vale tener palancas que dinero}

La estructura de este refrán es una comparación explícita "entre dos axiologías de las cuales la inferior, de acuerdo con el refrán, es superior en apariencia"; ${ }^{44}$ se trata de una manera de transmitir un consejo utilizando el contraste (consejos contrastivos). En más vale tener

\footnotetext{
${ }^{43}$ Larissa Adler-Lomnitz, "Economía informal, redes sociales y confianza", en Antonio Azuela, coord., La corrupción en América, un continente, muchos frentes, México, uNAM-Instituto de Investigaciones Sociales, 2006, 109.

${ }^{44}$ Herón Pérez Martínez, Refrán viejo nunca miente, p. 163.
} 
GrÁFICA 6. Uso del refrán Mas vale tener palancas que dinero según edad

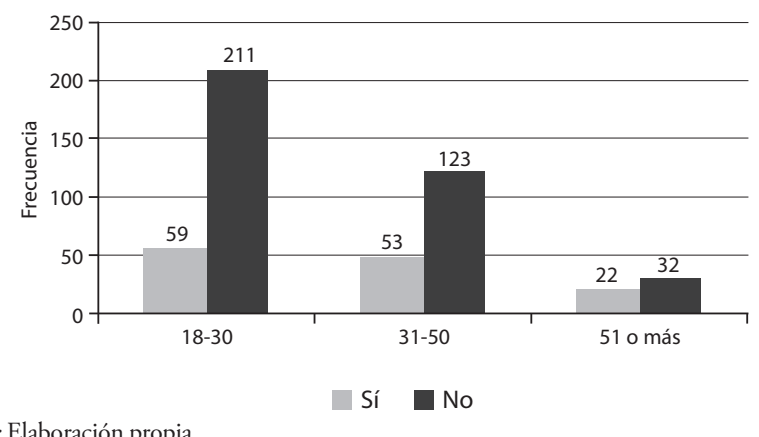

Fuente: Elaboración propia.

palancas que dinero se trata de una comparación nominal donde el verbo se conserva (tener), y la contraposición se da entre las palancas y el dinero, dando más peso a tener palancas (algo no tangible) sobre el evidente valor de tener dinero.

Este refrán, aunque es conocido y muy relacionado con la corrupción (83\%), no es tan usado por la muestra encuestada (26.8\%); sin embargo, entre los que lo utilizan, la mayoría son hombres $(60 \%)$, mientras que $40 \%$ restante son mujeres; y aunque su uso no es tan frecuente, son las personas mayores de 50 años quienes más lo utilizan (41\%), mientras que entre los jóvenes solo lo hace 22 por ciento, como se aprecia en la gráfica 6 .

El uso de este refrán entre personas mayores no quiere decir, necesariamente, que sean ellos los más acostumbrados a usar palancas pero sí que el concepto no tiene una connotación tan negativa como para los jóvenes, y aflora en el habla cotidiana más fácilmente; además de que el concepto está más relacionado entre ellos con favores que con corrupción. En cuanto al uso de este refrán por niveles de escolaridad, en el gráfico se puede apreciar una diferencia más marcada entre los de escolaridad alta que en los de baja:

En la gráfica 7 es identificable que en el grupo de los que tienen estudios de posgrado, 24 por ciento sí lo usa, mientras que entre los 
GRÁFICA 7. Uso del refrán Mas vale tener palancas que dinero según escolaridad

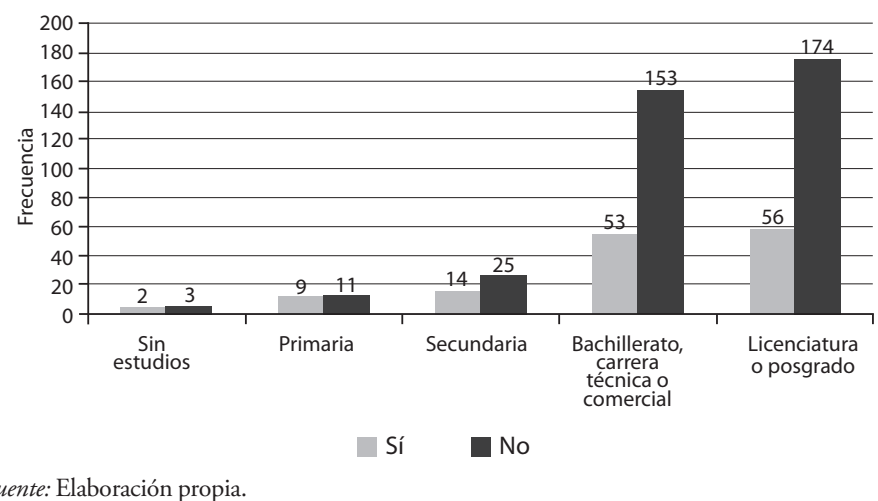

de primaria llega hasta 45 por ciento, sin que ello signifique que los de baja escolaridad sean más corruptos o estén más acostumbrados a usar el concepto de palanca en su vida cotidiana, pero sí que lo utilizan más; podía aventurarse la hipótesis de que la escolaridad sí influye en el grado de conocimiento sobre lo que es corrupto o no, así como en el conocimiento sobre el significado social de palanca, por lo que, tal vez, aunque los de alta escolaridad lo usen no lo declaran públicamente. Si es cierto que el nivel educativo produce comportamientos diferenciados respecto a la corrupción, ésta podría ser una vía para su combate, lo que se complementa con la tendencia observada en la siguiente gráfica de que a mayor nivel socioeconómico, menor uso de este refrán, aspecto que es medido indirectamente a partir del número de focos que tiene su casa (véase gráfica 8 ).

Sin embargo, esta correlación podría ser el resultado del nivel educativo que también va asociado al nivel socioeconómico y no que necesariamente los pobres usen más las palancas, aunque ésta también es una hipótesis que se deberá explorar en otro estudio.

Palanca es un concepto muy relacionado con la corrupción; constituye parte del lenguaje especializado que se utiliza coloquialmente para referirse a una ayuda poderosa para lograr algo, por medios no convencionales. La palabra proviene de latín palanga, y a su 
Gráfica 8. Uso del refrán Mas vale tener palancas que dinero según nivel socioeconómico

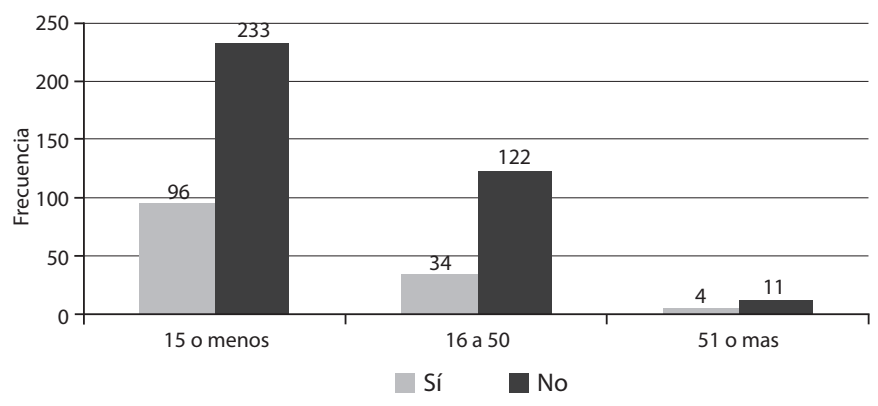

Rangos de nivel socioeconómico (medido a partir del número de focos en casa)

Bajo $=15$ o menos $\quad$ Medio $=$ entre 16 y $50 \quad$ Alto $=$ más de 50

Fuente: Elaboración propia.

vez del griego $\phi \lambda \alpha \gamma \xi$, que significa garrote; ${ }^{45}$ se trata de una barra flexible apoyada en un punto para transmitir fuerza; es una máquina simple que amplifica la fuerza aplicada a un objeto. El propósito del uso de la palanca es optimizar el esfuerzo, idea que prevalece en el lenguaje de la corrupción, donde tener palancas significa "tener las suficientes influencias y complicidades como para remover cualquier obstáculo que se nos atraviese en la vida" ${ }^{46}$

El refrán más vale tener palancas que dinero, pone en evidencia el hecho de que a pesar de la importancia que el dinero tiene en la fraseología popular, todavía es más importante tener palancas; en la vida diaria "hay que tener palancas para acomodarse. Sí, ya sea para encontrar trabajo, tiene que haber palancas, para resolver algún problema tiene que haber palancas, para conseguir alguna concesión sólo es por palancas". ${ }^{47}$ Tener palanca(s) significa tener un trato preferencial en cierto trámite: "Si vas con el funcionario fulano, ahí te vas a evitar todos los trámites y vas a ir directo"; ${ }^{48}$ todos aquellos que

\footnotetext{
${ }^{45}$ Real Academia Española en http://www.academia.org.mx/rae.php.

${ }^{46}$ Germán Dehesa, op. cit., p. 123.

${ }^{47}$ Entrevista con A. Pérez (20/III/2009).

${ }^{48} \mathrm{Ibid}$.
} 
se consideran amigos o, al menos conocidos del funcionario, buscan evadir los trámites pretendiendo algún tipo de trato preferencial.

Existen funcionarios públicos que se manejan con palancas y otros que se apegan a las reglamentaciones;

cuando un funcionario público se maneja por palancas, [...] ve diferentes grupos de personas, los amigos, los que le pueden favorecer a él y los que no le van a dar ningún beneficio [...] a los amigos y a los que le pueden dar beneficio, les trata con preferencias o con palancas y a los que no pueden darle ningún beneficio los margina, los hace a un lado. ${ }^{49}$

Por lo tanto, la palanca es un procedimiento injusto que ayuda a unos por sobre los otros; no sólo se trata de ayudar como la creencia popular lo enfatiza, se trata de relegar a los otros que no tienen conocidos o palancas que los ayuden, contribuyendo al tortuguismo burocrático que empuja a los usuarios a la búsqueda de caminos más ágiles, aunque ilegítimos, para sacar adelante un trámite.

En ocasiones, la administración pública es muy enredosa, complicada y con una tramitología grandísima, y sólo con palancas se puede sacar adelante cierta diligencia, pero para aquellos que no cuentan con ellas, intervienen algunos actores para agilizar los trámites tardados, complicados y engorrosos, ellos son el gestor y el coyote. El coyote es una persona que ofrece "su intermediación entre el ciudadano y alguna dependencia oficial. Mediante una paga, el coyote nos ofrece agilizar un trámite, obtener una licencia, conseguir lo inconseguible" ${ }^{50} \mathrm{El}$ trámite puede ser simple o complicado, porque frecuentemente se parte del desconocimiento del usuario de dicha gestión, "un gestor es un coyote venido a más o un coyote con oficina [...] [que] quiere parecer funcionario". ${ }^{1}$ Se trata de un coyote exitoso, o al menos eso quiere aparentar, lo que repercutirá en mayor confianza por parte de aquél que solicite sus servicios. Tanto el coyote como el gestor deben recurrir a sus "contactos" para conse-

\footnotetext{
${ }^{49} \mathrm{Ibid}$.

${ }^{50}$ Germán Dehesa, op. cit., p. 57.

${ }^{51} I d$., p. 85.
} 
guir sacar adelante algo que sólo se puede por la vía legal; el "contacto" es aquel que en el ámbito de la corrupción se encarga de realizar el trámite de cualquier asunto, dentro de su función pública y gana por ello un ingreso complementario. Para ser un buen "contacto" hay que tener determinado puesto, o cierto valimiento frente a la autoridad. "Los servicios de un 'contacto' se recompensan de dos maneras: en metálico [lo más barato], o ingresando al 'banco de los favores' [lo más costoso]". ${ }^{52}$

Una variante de tener palanca es tener charola o placa de policía, judicial o político, que en este mundo de la corrupción equivale a una credencial de gran poder donde la palanca aparenta constituirse en la llave mágica que soluciona todos los problemas a los que nos enfrentamos en la vida diaria y que puede ser usada en cualquier situación, sin embargo, pareciera haber ciertas áreas donde es más factible su uso; Dehesa lo asocia a los lugares donde se utilizan documentos porque ellos constituyen la materia prima para su funcionamiento: "Los documentos son a la corrupción lo que el petróleo es a la industria: el energético indispensable" ${ }^{53}$ Es ante la premura de los trámites urgentes y el tortuguismo de la administración pública que aparece el coyote con toda su manada, el burócrata, el funcionario, el agente dispuesto a cooperar para que el trámite se agilice.

Existen áreas de la administración pública que sólo con palancas funcionan, por ejemplo, la Junta Local de Conciliación y Arbitraje, donde los documentos se mueven al compás de los billetes: las audiencias se cambian de lugar o de hora, "o las notificaciones no se hacen o se tardan o se hacen rapidísimo porque hubo palanca y entonces ya se la hicieron, pero si uno se espera al procedimiento normal ¡ummm! le van a dar tres semanas". ${ }^{54}$ En el campo de las relaciones laborales, también "se da bastante la palanca en el sentido de que o el empresario tiene un problema laboral y le habla a fulano aparte y le diga a zutano: oye pues es que ese problema, para que no se me vaya a ir de las manos y se maneje bien, o un líder sindical que

${ }^{52} I d .$, p. 44.

${ }^{53} I d$., p. 63.

${ }^{54}$ Entrevista con A. Pérez (20/III/2009). 
va y presiona y dice: esto tiene que ser de esta manera". ${ }^{55}$ La palanca se constituye en una herramienta indispensable para superar los problemas o tener un dictamen favorable en asuntos que son desconocidos para la mayoría de los trabajadores involucrados. "En cuestiones de seguridad, todavía se da el uso de la palanca: oye, que a mí me sucedió esto, pues a ver si le investigas para saber quién fue" ${ }^{56}$ En los trámites ante el Ministerio Público o en las policías se da mucho lo de palancas a través de llamarle a algún conocido: "Si se da un robo por ejemplo o si se da un choque o si hay algún delito, etcétera, sí, se observa que hay el telefonazo, el triangular; le hablo a fulano pero para que le diga a perengano y que se agilice el trámite". ${ }^{57}$

Las palancas también son usadas en el campo de los servicios médicos, sobre todo en los del sector público, destacando el Instituto Mexicano del Seguro social (IMSS) y el Instituto de Seguridad Social para los Trabajadores del Estado (ISSSTE), donde la palanca opera a través de la triangulación; si se tiene una urgencia se buscará al conocido del médico o del director para lograr un mejor servicio: "oye fulanito, háblale a perenganito para decirle que ahí va mi familiar para que lo atiendan mejor"; ${ }^{58}$ la triangulación se trata de un favor pedido indirectamente a un influyente no conocido directamente, a través de otro que opera como contacto; se trata de una cadena de favores para dar un trato preferencial a uno sobre la desatención a otros. No se trata de dinero sino de un compromiso que luego deberá ser pagado al precio que se solicite, cuando algún otro de la cadena requiera un favor. Para tener acceso a la educación pública también se puede con palancas: para ingresar a un jardín de niños, a una primaria, a una secundaria, escuela técnica o a la universidad, siempre habrá un conocido en la Secretaría de Educación Pública (SEP), en el Instituto de Educación o en la escuela donde se quiera ingresar. Los favores se pueden pedir desde a la inspectora del jardín de niños, al funcionario de la SEP, a la directora o director de la escuela o a un simple maestro $\mathrm{o}$ al intendente que conoce a otra persona de más alto rango.

$$
\begin{aligned}
& { }^{55} \text { Ibid. } \\
& { }^{56} \text { Ibid. } \\
& { }^{57} \text { Ibid. } \\
& { }^{58} \text { Ibid. }
\end{aligned}
$$


La palanca puede darse o no, tal vez no puede faltar alguien que haga valer un derecho o tan sólo crear confianza en el solicitante de la ayuda, pero lo que importa es que la gente cree que únicamente a través de mecanismos en los que interviene una persona pudiente es como se logra con éxito obtener el tan buscado lugar o agilizar el trámite. En ocasiones se generaliza la creencia de que a ciertas instituciones, como las universidades, sólo se puede entrar con palancas: "se escucha, se dice que si tienes una palanca puedes entrar a estudiar fácilmente; a mí no me consta porque pues yo no tuve nadie que me ayudara ni nada y tampoco he sabido de nadie que haya entrado a la universidad por alguna palanca, pero no lo dudo que exista (risa)" ${ }^{59}$ En la contratación de personal, tanto en las empresas privadas como en la administración pública frecuentemente aparece el nepotismo o el tráfico de influencias para obviar los exámenes de selección, y en un sinfín de situaciones, siempre aparece la palanca para garantizar el éxito.

A partir de ir identificando el entretejido que se elabora para el uso de palancas, una pregunta brota de manera natural ¿tener palancas es tener amistades?, y como consecuencia, si es un favor ¿qué de malo tiene? Esta discusión no es planteada en la vida diaria, y mucho menos por los beneficiarios de su uso, porque es el barniz de favor el que legitima el uso de las palancas en la vida cotidiana. Los entrevistados, en varias ocasiones, trataron de diferenciar a la palanca de las amistades: "a veces vale más tener una amistad que es la que te ayuda a hacer todo mucho más fácil"; ${ }^{60}$ otro dice, haciendo alusión al refrán más vale tener palancas que dinero: "yo más bien cambiaría más vale tener conocidos que dinero" ${ }^{61}$ La palanca se confunde con el favor cuando no hay dinero de por medio, y en algunas ocasiones se trata de un acto desinteresado, aunque frecuentemente se adquiere una deuda que deberá ser pagada en el futuro con otro favor: favor con favor se paga, dice un dicho popular.

\footnotetext{
${ }^{59}$ Entrevista con Francisco (26/VIII/2009).

${ }^{60}$ Entrevista con Eduardo (07/IV/2009).

${ }^{61}$ Entrevista con Francisco (26/VIII/2009).
} 
La palanca puede estar vinculada con el dinero, sobre todo cuanto intervienen otros actores como el gestor o el coyote, pero normalmente se trata exclusivamente de amistad, sea de manera directa o indirecta, mediada por otra persona, el "contacto"; "Probablemente en alguna ocasión, en reconocimiento de la palanca, se haga algún regalo", ${ }^{62}$ pero normalmente la palanca opera en el ámbito de los favores, "aunque es un favor mal habido" 63 y va creando un compromiso con la persona que lo hizo, por ello algunas personas buscan hacerle un favor a una persona importante, bien colocada o con influencias, porque establecerá un compromiso de devolver el favor, además de que "el que hace una palanca una vez ya está comprometido a volverlo a hacer" ${ }^{64}$ La palanca aparece relacionada con todo un campo semántico de conceptos que están relacionados con ella: favoritismo, predilección, parcialidad, arbitrariedad, polacada, atropello, injusticia, chanchullo, abuso, alcaldada, nepotismo, y en general tráfico de influencias, que nos lleva a una situación social de inequidad en la que en ocasiones podemos resultar beneficiados de manera individual, pero como sociedad nos perjudica.

\section{El gandalla no batalla}

“El término 'gandalla' es un neologismo, aún no validado por la Real Academia, pero de uso común en nuestro país". ${ }^{65}$ Según lo documentado por Carlos Montemayor, ${ }^{66}$ el sentido que le damos en México data de 1646, en la novela picaresca tardía Estebanillo, donde aparece como sinónimo de ociosidad y bribonería; pero existe en España y en otros países latinoamericanos un significado diferente que lo asocia a una red que se coloca para cubrir el cabello. En México, la palabra se utiliza para referirse a una persona y a acciones re-

\footnotetext{
${ }^{62}$ Entrevista con A. Pérez (20/III/2009).

${ }^{63}$ Ibid.

${ }^{64}$ Ibid.

${ }^{65}$ Enrique Romero, Al que no agandalla, se lo agandallan, en http://lacasadeljabonero.blogspot.com/2008/03/6-de-marzo-del-2008.html.

${ }^{66}$ Carlos Montemayor, "Sobre los mexicanismos gandalla y agandallar", en La Jornada, miércoles 7 de enero de 2009, Sección Cultura.
} 
feridas al concepto, utilizando la palabra como verbo (agandallar, agandallarse, etcétera). En su evolución, la forma verbal sufrió una distorsión producto del uso incorrecto de la palabra, de tal manera que aunque originalmente se usaba en el contexto catalán engandallarse para referirse al acto de ponerse la cofia o red ya mencionada, en México usamos el verbo como agandallarse o agandallar. Se trata de una expresión más relacionada con la gente joven, aunque realmente es usada por todos. Es un dicho muy conocido y muy relacionado con la corrupción (74\%), sin embargo, es una expresión cargada de una connotación negativa y fácilmente relacionada con la corrupción, por lo que la mayoría niega usarla $(86 \%)$ y, de entre los que la expresan, la mayoría son hombres (63\%).

El dicho el gandalla no batalla denota una procedencia urbana que Montemayor ubica en los bajos fondos de la frontera norte o de las grandes ciudades del país, aunque la mayoría de nuestros entrevistados seńala su uso mayormente ligado al Distrito Federal.

En una encuesta emprendida por un programa de radio, hace tres años, se hizo la pregunta ¿qué es para ti ser un gandalla? Lo que fue respondido por varias personas a través de un blog, ${ }^{67}$ donde se pueden apreciar respuestas muy interesantes, pero lo que ahora interesa destacar es que ninguno de los que ahí respondieron se consideró gandalla, aunque varios de ellos señalan que en algún momento de nuestra vida lo podemos ser, y eso se debe al premio social de aprovechar las oportunidades, que es como se considera popularmente ser gandalla. En la actualidad, ser gandalla está de moda porque significa aprovechar las oportunidades y ser superior a los demás, vivir bien $y$, aunque no sea bien visto, ser importante en un mundo donde si no se es gandalla se es víctima, agandallado. Ejemplos abundan:

Cuando alguien se mete hasta adelante en el tráfico sin formarse es gandalla, el que se estaciona en doble y triple fila para dejar a sus hijos frente a las escuelas obstruyendo el tránsito y que todavía se quedan a comadrear, el

${ }^{67}$ Blog en http://mx.answers.yahoo.com/question/index?qid=20070117075935 AAXBZAh . 
que en el condominio ocupa espacios comunes, maltrata las áreas verdes o las ensucia su perro, o bien que cuando hace sus fiestas molesta a los demás vecinos con la música muy alta sin dejar dormir y que además estaciona los autos de sus invitados en donde estorban. ${ }^{68}$

La idea generalizada del gandalla no es la de un bandolero como antaño, ni siquiera la de un delincuente, pero sí es un ser desagradable y mal visto, "es el que sin tener ni el derecho ni la razón se apropia, normalmente por el uso de la fuerza o el temor de la víctima, de algo que no le corresponde por derecho propio". ${ }^{69}$ Se le considera antipático y naco con todo el sentido peyorativo del concepto: "El gandalla hace rato que salió del barrio, subió de nivel social y actualmente domina el campo de las finanzas", ${ }^{70}$ o el de la política o algún otro que le da ventaja sobre los demás.

Cuando el gandalla se encuentra en la arena política, que en opinión de Enrique Romero es su paraíso, ejerce el "gandallismo político", que consiste en ejercer esta actividad por encima de ideologías e intereses partidarios; igual se instala en la derecha o en la izquierda y cambia de bando según le conviene, porque se rige por "el postulado maquiavélico de "el fin justifica los medios", sólo que antes se hacía en lo obscurito y ahora se hace a cielo abierto" ${ }^{71}$ La situación es generalizada en la política y no se salva ningún partido, porque en todos podemos encontrar a este tipo de personajes que incluso pueden llegar a ser gobernantes.

El campo de la administración pública es otro paraíso para el gandalla, porque igual como ciudadano que como funcionario se corrompe: como funcionario pide dinero por trámites que debería hacer gratuitamente, ofreciendo hacerlos más pronto y bien, y aunque en algunas ocasiones lo cumple, cobra por algo que el erario público ya le está pagando. Si se trata de un ciudadano gandalla, al

${ }^{68}$ David en http://mx.answers.yahoo.com/question/index?qid=20070117075935A AXBZAh.

${ }^{69}$ Enrique Romero, Al que no agandalla, se lo agandallan, en http://lacasadeljabonero.blogspot.com/2008/03/6-de-marzo-del-2008.html.

${ }^{70} \mathrm{Ibid}$.

${ }^{71} \mathrm{Ibid}$. 
hacer fila en cualquier trámite común se va acercando y llega a la ventanilla antes que los demás; es también el que ofrece dinero a un servidor público a cambio de hacer su trámite más rápido o para poderlo hacer aunque no cumpla todos los requisitos. En este caso sí podría tratarse de corrupción porque se tratará de soborno y cohecho, aunque ellos lo maquillarán de benevolencia y ayuda al prójimo y le llamarán favor.

En esta cultura de la corrupción sólo sobrevive el más fuerte, el que arrebata, el que despoja, el que pisotea el trabajo, la dignidad y los derechos de los demás; el que se vale de cualquier método para lograr sus propósitos sin importar los medios, el gandalla que siempre encontrará una justificación para cualquier acto indebido al señalar "si los policías son corruptos, es por culpa de los funcionarios de gobierno, pues les pagan una porquería. Si les pagaran como en otros países, jamás aceptarían nuestras mordidas" ${ }^{72} \mathrm{El}$ gandalla es el que transa en infinidad de situaciones porque tiene como filosofía de vida que el que no transa no avanza, y por ello trata de aprovechar todas las situaciones para su beneficio, fanfarroneando por su habilidad.

Ser gandalla o agandallar no constituye un delito tipificado como corrupción, o como alguna de sus variantes. ${ }^{73}$ En la mayoría de los casos, sin embargo, 74\% de la muestra, mayores de edad, de la ciudad de Aguascalientes y sus alrededores consideró que la expresión El gandalla no batalla está relacionada con corrupción, lo que nos hace suponer que la concepción de corrupción que prevalece entre ellos es la de algo descompuesto, echado a perder, putrefacto, a lo que también se asocia la idea de gandalla:

CuAdro 6. Ilustración sobre la relación entre la corrupción y el gandalla

\begin{tabular}{c} 
Corrupción $=$ malo $\quad$ malo = gandalla \\
\hline Corrupción $\leftarrow \rightarrow$ Gandalla \\
\hline
\end{tabular}

Fuente: Elaboración propia.

\footnotetext{
${ }^{72}$ Poncho Vera, Manual del perfecto gandalla, México, Ediciones B, 2008, 130.

${ }^{73}$ Soborno, cohecho, tráfico de influencias, extorsión, peculado o fraude.
} 
Como se puede apreciar, la relación entre gandalla y corrupción no es directa, sino por asociación; el gandalla tiene todo lo malo que asociamos a la corrupción, pero ello no quiere decir que no esté exento de cometer un acto de corrupción, por el contrario, aunque no lo haga todos lo vinculamos a ella porque esa falta de valores éticos y morales que lo caracteriza lo hace susceptible de caer en ella, aunque nunca lo haga.

\section{Conclusiones}

Estudiar a la sociedad a través del lenguaje permite conocer dimensiones que desde otras perspectivas no se lograrían; uno de los retratos más precisos de los individuos y de su entorno es el registro de las palabras que se usan, las locuciones con las que se expresan a diario: en dónde, con quién y ante qué situaciones lo hacen, porque el hecho de asignar nombres es, en sí mismo, no solamente un acto de apropiación conceptual, sino también de construcción del mundo.

El habla lapidaria, como cultura popular, contribuye a la apropiación conceptual del mundo de la vida cotidiana, y a su construcción a través del sentido común. Los dichos y refranes sobre la corrupción, por una parte le dan a ese fenómeno un sentido peculiar, propio de la sociedad y de los grupos sociales que los usan, y por otro contribuyen a su reproducción justificándola, aunque aquí nos atrevemos a pensar que también pudieran contribuir a combatirla. Como dice Germán Dehesa: "toda corrupción comienza con el lenguaje y toda lucha por extirparla también tendrá que comenzar aunque no agotarse- en las palabras". ${ }^{74}$

Lo que han buscado las palabras de este artículo es hacer visibles dos realidades, la vida cotidiana y el sentido común de la cultura popular, para mostrar cómo se relacionan y se retroalimentan en el terreno específico de la corrupción. El hilo conductor de nuestra exposición ha sido, precisamente, ir señalando cómo se entretejen las acciones comunes de la corrupción, que son comunes en el doble sentido de ser practicadas por la mayoría de los miembros de una

${ }^{74}$ Germán Dehesa, op. cit., p. 15. 
sociedad y de ser cotidianas, con el sentido también común de la cultura popular que, expresándose por medio de los dichos y refranes, dota de sentido, justifica, legitima, y eventualmente combate, esas acciones.

La vida cotidiana se refiere a las acciones que no son extraordinarias porque no se llevan a cabo solamente en ocasiones especiales sino todos los días, como levantarse, vestirse, comer, platicar, caminar por el pueblo, por el campo o por la ciudad, dormir, trabajar, etcétera, y porque son realizadas por sujetos comunes, no por grandes personajes o por actores colectivos. Desafortunadamente, en nuestro país la corrupción pertenece a esta clase de acciones de todos los días, que es realizada por los sujetos comunes. 75 "La corrupción somos todos" fue una expresión con la que el ingenio popular corrigió el eslogan "la solución somos todos", de la campaña de un candidato a la presidencia de la república.

El sentido común, para Clifford Geertz, es el correspondiente cultural de la vida cotidiana, porque no sólo forma el telón de fondo sobre el que se interpreta la experiencia, sino que es un poderoso mecanismo de su legitimación: "Ninguna religión es más dogmática, ninguna ciencia es más ambiciosa, ninguna filosofía es más general". ${ }^{76}$ El habla lapidaria es así. Como lo señalamos en el cuerpo del trabajo, los dichos y refranes son expresiones sentenciosas, agudas, silogismos abreviados, concisos, que para quienes los expresan constituyen pequeñas dosis de saber. Son parte de la lógica práctica que para una comunidad de hablantes se ubica en el terreno de lo razonable, más que de lo racional, porque deriva su fuerza argumentativa precisamente de la relación entre el lenguaje y la experiencia, entre el sentido y las acciones. El que no transa no avanza, ¿cómo nos arreglamos?, más vale tener palancas que tener dinero, y el gandalla no batalla, son dichos que enuncian argumentos "lógicos" cuando se refieren a situaciones específicas reforzadas por la experiencia. Así,

\footnotetext{
${ }^{75}$ Aunque desde luego existe también la corrupción política, o gran corrupción, que involucra grandes cantidades de dinero en cada transacción, y a burócratas o políticos en altos puestos.

${ }^{76}$ Clifford Geertz, Local Knowledge. Further Essays in Interpretive Anthropology, Londres, Fontana Press, 1993, 84.
} 
vida cotidiana y sentido común se entrelazan para reproducir la corrupción.

Pero el sentido común, como la experiencia de la vida cotidiana, no son sistemáticos. Igual se puede decir que al que madruga Dios le ayuda, que no por mucho madrugar amanece más temprano. Cómo pueden los dichos y refranes convertirse en aliados de la lucha contra la corrupción, es una pregunta que este trabajo deja abierta.

\section{BibliografíA}

Adler-Lomnitz, Larissa, "Economía informal, redes sociales y confianza", en Antonio Azuela, coord., La corrupción en Améri$c a$, un continente, muchos frentes, México, UNAM-Instituto de Investigaciones Sociales, 2006.

Aroca, Rubén, Corrupción, elites y democracia, en http://www.monografias.com/trabajos5/corrupc/corrupc.shtml

Chávez Torres, Rafael, "La transa económica" en Revista Escrutinio. La mirada crítica, 8 de septiembre de 2009.

DenesA, Germán, ¿Cómo nos arreglamos? Prontuario de la corrupción en México, México, Editorial Diana, 2001.

Fernández Ríos, Luis, Psicología de la corrupción y los corruptos, Granada, Grupo editorial Universitario, 1999.

FrENK, Margit, "Folklore vivo/folklore tránsito: en torno al cancionero folklórico de México", en Arturo Chamorro Escalante, ed., Sabiduría Popular, Zamora, El Colegio de Michoacán, 1997.

GeERTz, Clifford, Local Knowledge. Further Essays in Interpretive Anthropology, Londres, Fontana Press, 1993.

GonZÁLEZ, Luis, "Introducción. La historia contada, cantada y para verse", en Arturo Chamorro Escalante, Sabiduría Popular, Zamora, El Colegio de Michoacán, 1997.

Guzmán, Josefina y Pedro Reygadas, De refranes y cantares tiene el pueblo mil millares I. Refrán mexicano y discurso: tipología, camposy estructuras recurrentes en el universo de la oralidad, San Luis Potosí, UASLP, Unidad de Publicaciones de El Colegio de San Luis, 2009.

Lomnitz, Claudio, coord., Vicios públicos, virtudes privadas: la corrupción en México, México, CIESAS, Miguel Ángel Porrúa, 2000. 
Montemayor, Carlos. "Sobre los mexicanismos gandalla y agandallar”, en La Jornada, Sección Cultura, miércoles 7 de enero de 2009.

Pérez Botello, María Teresa, "El refrán como texto oral y escrito", en Estudios Sociales, nueva época, núm. 2, 2007, 183-197.

Pérez Martínez, Herón, "La investigación paremiológica en México”, en Herón Pérez y Raúl E. González, eds., El folclor literario en México, Zamora, El Colegio de Michoacán, Universidad Autónoma de Aguascalientes, 2003.

, "Refranes y refraneros", en Arturo Chamorro Escalante, ed., Sabiduría Popular, Zamora, El Colegio de Michoacán, 1997.

-, Refrán viejo nunca miente, Zamora, El Colegio de Michoacán, 1997.

_, En pos del signo. Introducción a la semiótica, Zamora, El Colegio de Michoacán, 1995.

_- El hablar lapidario: ensayo de paremiología mexicana, Zamora, El Colegio de Michoacán, 1995.

Romero, Enrique, "Al que no agandalla, se lo agandallan", en http: //lacasadeljabonero.blogspot.com/2008/03/6-de-marzo-del- 2008. html

Rose-Ackerman, Susan, "La economía política de la corrupción", en Ann Elliot Kimberly, La corrupción en la economía global, México, Limusa, 2001.

Vera, Poncho, Manual del Perfecto Gandalla, México, Ediciones B, 2008.

ZALPA, Genaro, ¿No habrá manera de arreglarnos? Corrupción y cultura en México, en proceso de publicación.

\section{Fuentes ELECTRÓNICAS}

Blog en http://mx.answers.yahoo.com/question/index?qid=20070 117075935AAXBZAh.

Corrupción en México en http://www.bajaeco.com/hablemos/corrupcion.cfm (consultada 06/XII/09).

Real Academia Española en http://www.academia.org.mx/rae.php 
Transparencia y combate a la corrupción, en http://www.ciad.mx/ contraloria/transparencia.html (consultado 09/IV/10).

\section{ENTREVISTAS}

Entrevista con A. Pérez (realizada 20/III/2009)

Entrevista con Eduardo (realizada 07/IV/2009)

Entrevista con Francisco (realizada 26/VIII/2009)

Entrevista con Marco Antonio (realizada 3/XI/2008)

Entrevista grupal (Elisa, Luis e Iván) (realizada13/X/2009)

FeCHA DE RECEPCión DEL ARTículo: 30 de junio de 2010

FECHA DE ACEPTACIÓN Y RECEPCIÓN DE LA VERSIÓN FINAL: 31 de enero de 2011 